\title{
The Fuzzy Synthetic Evaluation Model on Coaches
}

\author{
Lei Li \\ School of Electric Power Engineering, North China Electric Power University, Baoding 071000, \\ China
}

1010898691@qq.com

Keywords: AHP; Fuzzy synthetic evaluation.

\begin{abstract}
This article is a comprehensive evaluation problem. We build a fuzzy synthetic evaluation model. Start with the performance of the coaches' teams only and establish an AHP model according to the official data, in order to rank all the coaches by an overall evaluation. Then according to this rank, select some outstanding coaches, and complement their relevant information, including ethics (Q1), level of training (Q2), the industry contribution (Q3), and social recognition, Combine grey system theory and AHP to comprehensively evaluate the selected coaches.
\end{abstract}

\section{Introduction}

Coach is an important figure of a team who plays a guiding role in the game, the Sports Illustrated magazine organized an American college coaches competitions. This problem requires building definite evaluation indexes and comprehensive evaluation mathematical model according to the official data[1], in order to filter out the Top 5 coaches of America in each kind of sports for the previous century. And whether time line does make sense in coaches' ability should be discussed as well. Analyze whether this evaluation model can be applied under the conditions of different genders and different types of sports.

\section{Assumptions}

Assuming that all teams' initial capacity is equal.

Assuming that the original data is authentic.

Experts do not communicate with each other, nor do they disturb each other in the process of scoring in the indicators.

\section{Parameters}

Table 1 Symbols and Definitions

\begin{tabular}{cc}
\hline Symbol & Meaning \\
\hline Q1 & Ethics \\
Q2 & Level of training \\
Q3 & The industry contribution \\
Q4 & Social recognition \\
\hline
\end{tabular}

\section{Gray fuzzy comprehensive evaluation model based on AHP}

\subsection{The evaluation index}

By discussion, the final evaluation indexes turn out to be four: professional ethics, team-training ability, contribution to the sports, and the Associated Press score (AP score).

An excellent coach should be honest, fair, ambitious, caring team members, and agglomerate a team. This index is in respect of working attitude to evaluate.

The basic duties of coaches are to train the team, his training techniques and training results are essential element to evaluate a coach. This index is in respect of team-training to evaluate. 
Industry contribution is the honor that a coach's team achieves. The more excellent a coach is, the more contributions to the college he makes. This index is in the respect of college to evaluate.

\subsection{Model building}

According to the gray fuzzy theory and fuzzy evaluation method [2][3] as follows:

(1) According to AHP, build factor set, comment set and the evaluation sample matrix

Let factor set $U=\left\{u_{1}, u_{2}, \ldots, u_{m}\right\}$, the comment set $V=\left\{v_{1}, v_{2}, \ldots, v_{p}\right\}$. The evaluation value sample which obtained from the evaluation of the k-th evaluation team member's (denoted by $Z_{k}$ ) for the j-th index is denoted by $d_{k j}$.

(2) Determine the evaluation gray class

According to the materials we refer to, whiten weight function can be determined by grey level.

For “excellent” grey class,

$$
f_{1}\left(d_{l i}\right)=\left\{\begin{array}{l}
\frac{d_{l i}}{9}, d_{l i} \in[0,9] \\
1, d_{l i} \in[9,+\infty] \\
0, d_{l i} \in[-\infty, 0]
\end{array}\right.
$$

For "good” grey class

$$
f_{2}\left(d_{l i}\right)=\left\{\begin{array}{c}
\frac{d_{l i}}{7}, d_{l i} \in[0,7] \\
2-\frac{d_{l i}}{7}, d_{l i} \in[7,14] \\
0, d_{l i} \notin[0,14]
\end{array}\right.
$$

For “medium” grey class,

$$
f_{3}\left(d_{l i}\right)=\left\{\begin{array}{c}
\frac{d_{l i}}{5}, d_{l i} \in[0,5] \\
2-\frac{d_{l i}}{5}, d_{l i} \in[5,10] \\
0, d_{l i} \notin[0,10]
\end{array}\right.
$$

For “poor” grey class

$$
f_{4}\left(d_{l i}\right)=\left\{\begin{array}{c}
1, d_{l i} \in[0,2] \\
\frac{4-d_{l i}}{2}, d_{l i} \in[2,4] \\
0, d_{l i} \notin[0,4]
\end{array}\right.
$$

(3) Calculate the gray statistics

According to the gray statistics, we can work out the weight $f_{i}\left(d_{k j}\right)$ of the i-th evaluation class according to the whitening weight function determined by the grey number, thus figure out the grey statistics $n_{j i}$ and the sum of grey statistics $n_{j}$, where

$$
n_{j i}=\sum_{k=1}^{p} f_{1} d_{k j}, n_{j}=\sum_{i=1}^{m} n_{j i}
$$

(5) Calculate the comprehensive evaluation value of evaluation index set $U$

Grey weight value of the i-th evaluation class of the $\mathrm{j}$-th index which is integrated by the all $\mathrm{r}$ evaluation team members is denoted by $r_{j i}=n_{j i} / n_{j}$. Use grey fuzzy evaluation method to process the former results, comprehensive evaluation vector of evaluation index set $\mathrm{U}$ is denoted by $B=W^{T} \circ R$, 
where "o" is fuzzy comprehensive evaluation operator. This model operator “०” is equal to the weighted average.

$$
B=\left(b_{1}, b_{2}, \ldots, b_{m}\right)=\mathrm{w}^{T} \cdot R=\left(w_{1}, w_{2}, \ldots, w_{n}\right) \cdot\left[\begin{array}{cccc}
r_{11} & r_{12} & \ldots & r_{1 m} \\
r_{21} & r_{22} & \ldots & r_{2 m} \\
\ldots & \ldots & \ldots & \ldots \\
r_{n 1} & r_{n 2} & \ldots & r_{n m}
\end{array}\right]
$$

If evaluation level set V's value vector $C=\left(c_{1}, c_{2}, \ldots, c_{m}\right)$, then the evaluation index set Q's rating value:

$$
\begin{aligned}
Q & =C \cdot B^{T}=\left(c_{1}, c_{2}, \ldots, c_{m}\right) \cdot\left(b_{1}, b_{2}, \ldots, b_{m}\right)^{T} \\
P & =\sum_{i=1}^{m} \lambda_{i} \cdot q_{i}
\end{aligned}
$$

Where $\lambda$ is the weight of each index, and $q$ is the score of each index.

\subsection{Model results}

Evaluate rating each ability of 5 excellent coaches' and put the results into the grey fuzzy evaluation model (the given value vector $C=[5,4,3,2]$ ), thus, quantitative evaluated results are got. Then assign weights to the four indexes according to AHP, the comprehensive score is calculated as follow:

$$
P=\sum_{i=1}^{m} \lambda_{i} \cdot q_{i}=0.1313 \cdot q_{1}+0.2627 \cdot q_{2}+0.4471 \cdot q_{3}+0.1589 \cdot q_{4}
$$

\begin{tabular}{|c|c|c|c|c|c|c|c|}
\hline Rank & \multicolumn{2}{|c|}{ Name } & Q1 & Q2 & Q3 & Q4 & Score \\
\hline 1 & Joe & Paterno & 7.5 & 9 & 8 & 9 & 4.2974 \\
\hline 2 & Bear & Bryant & 8.75 & 8.5 & 7.75 & 7.75 & 4.2445 \\
\hline 3 & Bo & Schembechler & 8.5 & 8.75 & 7.75 & 7 & 4.2332 \\
\hline 4 & Pop & Warner & 8.75 & 8.25 & 7.75 & 6 & 4.1937 \\
\hline 5 & AmosAlonzo & Stagg & 7.75 & 7.25 & 8.75 & 5 & 4.1929 \\
\hline
\end{tabular}

Where $q_{1}$ stands for professional ethics; $q_{2}$ stands for team-training ability; $q_{3}$ stands for industrial contribution; and $q_{4}$ stands for the AP score.

Table 2 The professional quality score of the first 5 football coaches

Put the coaches' quantized scores into the former formula to get the rank of coaches' professional quality. Each score of different coaches are little different, the maximum score is 4.2974, the lowest score is 3.9161, there's only a difference of 0.3813 , it shows that professional qualities of outstanding coaches are excellent.

\section{Time Line on the Evaluation Model}

In order to analyze the influence of the time, 1877-1999 years of data is divided into seven time periods, namely before 1900, 1900-1919, 1920-1939, 1940-1959, 1960-1979, 1980-1999. Take football data for example, calculate the average data of coaches at every stage of the indicators, and then fit the time series data with linear, the following is the results:

From the figure it can be seen: as time goes, the coaches winning percentage will gradually decrease. The average winning percentage of football coach is down from 0.60 to 0.42 . This is because of the raising of tournament level and the level of athletes. With the difficulty of the game gradually increasing, the teams get a high winning percentage is not so easy, therefore winning percentage gradually decreased. 


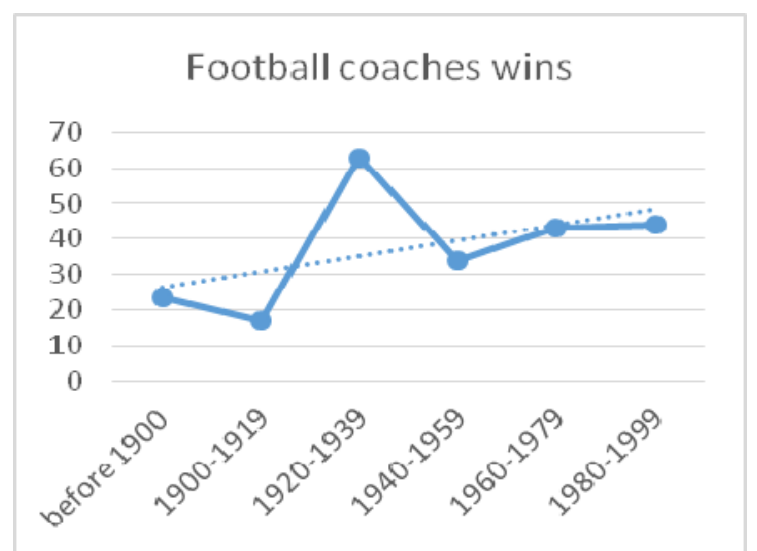

Fig. 2 Wins trends over time

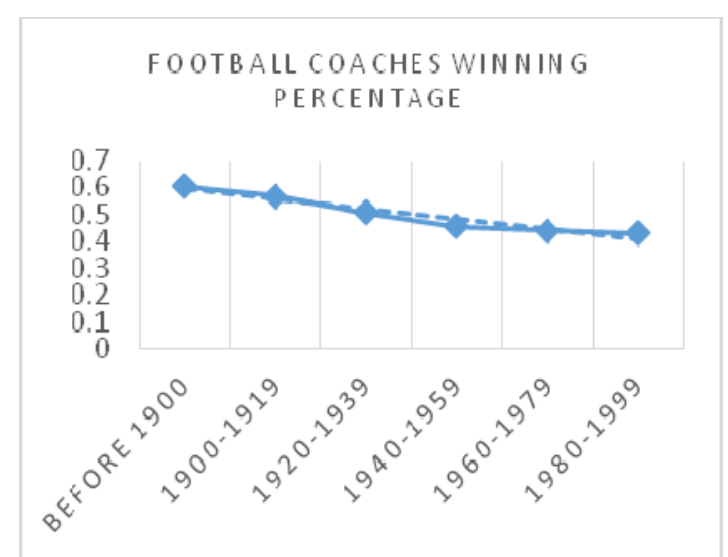

Fig. 3 Winning percentage curve over

The paper also selected the best coach of each period by the above model, the data in the table below:

Table 3 Great football coach of each period

\begin{tabular}{cccccccc}
\hline Time & Great Coach & Yrs & G & W & L & Pct & Score \\
\hline before 1900 & Pop Warner & 42 & 446 & 311 & 103 & 0.733 & 2.83 \\
$1900-1919$ & Dana Bible & 31 & 281 & 190 & 69 & 0.715 & 1.82 \\
$1920-1939$ & Jess Neely & 36 & 363 & 187 & 159 & 0.539 & 1.87 \\
$1940-1959$ & Bear Bryant & 38 & 425 & 323 & 85 & 0.78 & 2.79 \\
$1960-1979$ & Joe Paterno & 46 & 548 & 409 & 136 & 0.749 & 3.49 \\
$1980-1999$ & Mack Brown & 29 & 356 & 238 & 117 & 0.67 & 1.97 \\
\hline
\end{tabular}

If we analyze the representatives of each period, the change can be found that in wins and winning percentage are not regular, winning almost the same, just a slight difference in the score on the coaches. The influence of the times is not very significant for the great, so a great man is always ahead of its time, and they do not meet the general characteristics of that age, which is the great man's greatness.

\section{Reference}

[1] http://www.sports-reference.com/

[2]Chang N B, Chen $\mathrm{H} \mathrm{W}$, Ning S K, Identification of river water quality using the fuzzy synthetic evaluation approach[J]. Journal of Environmental Management, 2001, 63(3): 293-305.

[3]Chiou H K, Tzeng G H, Fuzzy hierarchical evaluation with grey relation model of green engineering for industry[J]. International Journal of Fuzzy Systems, 2001, 3(3): 466-475. 